Samantha Caesar de Andrade

Ágatha Nogueira Previdelli

Dirce Maria Lobo Marchioni

Regina Mara Fisberg

\section{Evaluation of the reliability and validity of the Brazilian Healthy Eating Index Revised}

OBJECTIVE: Evaluate validity and reliability of the Brazilian Healthy Eating Index Revised according to the psychometric properties.

METHODS: Cross-sectional study of a random sample of 2,375 individuals of both sexes, aged 12 or older from the city of São Paulo, Southeastern Brazil, drawn from the Health Survey carried out in 2003. Information on the population characteristics was acquired using a questionnaire. Food intake was obtained using 24h Recall, used to calculate the Brazilian Healthy Eating Index Revised (BHEI-R). The following aspects were evaluated: (1) content validity, by comparing the components with the Dietary Guidelines for the Brazilian Population; (2) construct validity, factor analysis using principal components method and verifying whether the index can measure diet quality regardless of energy intake; (3) discriminating validity; and (4) the reliability of the BHEI-R by analyzing the internal consistency of the items using Cronbach's alpha coefficient.

RESULTS: The correlations between the component scores and energy intake were weak $(r<0.30)$. Principal component analysis indicated the presence of four factors with eigenvalues $>1$ that represented $67 \%$ of the index variance. The discriminating validity of the BHEI-R was observed by comparing the individuals by sex and smoking habit, and identifying statistically significant differences between the means of the components of the BHEI-R and the final score. The Cronbach's alpha value $(\alpha=0.7)$ indicated the presence of internal consistency between the components of the BHEI-R. The SoFAAS component followed by the total fruit component and whole fruit component presented greater correlation with the final index scores.

CONCLUSIONS: The Brazilian Healthy Eating Index Revised showed itself to be reliable and structurally valid when used to evaluate and monitor the diet quality of Brazilians.

DESCRIPTORS: Diet, classification. Food Consumption. Nutrition Assessment. Quality Indicators, Health Care, utilization. Reproducibility of Results. Cross-Sectional Studies.

Departamento de Nutrição. Faculdade de Saúde Pública. Universidade de São Paulo. São Paulo, SP, Brasil

\title{
Correspondence:
}

Regina Mara Fisberg

Departamento de Nutrição

Av. Doutor Arnaldo, 715

01255-000 São Paulo, SP, Brasil

E-mail: rfisberg@usp.br 


\section{INTRODUCTION}

Dietary indexes allow individual's and/or population's adherence to nutritional recommendations to be assessed and monitored. ${ }^{14}$ Their use requires specific adaptations for each country to reflect the local reality. ${ }^{11}$ Fisberg et $\mathrm{al}^{8}$ adapted and validated the Healthy Eating Index (HEI) for the Brazilian population in 2004, giving the Brazilian Health Eating Index (BHEI).

With the appearance of the Food Guide for the Brazilian Population, created by the Ministry of Health in 2006, ${ }^{\text {a }}$ gaps were found in the BHEI which led to it being revised. Previdelli et $\mathrm{al}^{20}$ (2011) updated the index, developing the revised BHEI (BHEI-R), made up of 12 components based on energy density (portion/1,000 kcal) or by percentage share of calories in the diet, so as to reflect different aspects of the quality of the diet.

The instrument is being used to assess the quality of diet of population groups, ${ }^{b}$ but there are no studies on the psychometric properties of this version. The aim of this article was to evaluate the reliability and validity of the BHEI-R.

\section{METHODS}

Cross-sectional study with a probabilistic sample in the municipality of Sao Paulo, SP, Southeastern Brazil, made up of 2,375 individuals aged $\geq 12$, of both sexes, taking part in the Health Survey (ISA-Capital 2003). Details of the sample and the data collection from this study have been previously published. ${ }^{3}$ Data on characteristics of the population were obtained using a questionnaire, and food intake using the 24-hour recall method. Portion sizes were transformed into units of measurement and the nutritive value obtained using the Nutrition Data System for Research (NDS-R, version 2007) program. The Healthy Eating Index was then calculated (Table 1).

The performance of the BHEI-R was measured using strategies for assessing content validity, construct validity, discriminant validity and reliability, as proposed by Guenther et al (2008). ${ }^{12}$

\section{First stage: Content validity}

The components of the BHEI-R were compared with official nutritional guidelines from the Food Guide for the Brazilian Population ${ }^{\mathrm{a}}$ in order to evaluate whether they contained the key aspects of healthy eating recommended for the population.

\section{Second stage: Construct validity}

Nutrient intake is positively correlated with the quantity of energy consumed. Higher calorie diets may have an over estimated score as they are measured in absolute terms. ${ }^{12}$ To analyze whether the BHEI-R assesses the quality of the diet independently of the quantity of energy consumed, Pearson's correlation analysis was used on the final score of the components of the index and the energy.

Factor analysis was carried out using Principal Component Analysis (PCA). Based on the correlation between the 12 components to verify whether the structure of the BHEI-R has another dimension. The PCA is a statistical technique of multiple analysis which linearly transforms a set of original variables into a substantially smaller set of non-correlated variables which contain the majority of the information of the original set. All of the items were considered in the analysis. The matrix was obtained using varimax rotation. The criteria suggested by Kaiser ${ }^{13}$ (1958), who proposed only considering eigenvalues above one, were used to choose the number of factors to be kept in the model. The auxiliary method used was the Scree test; ${ }^{4}$ so the dispersion of the number of factors was analyzed until the individual variance curve for each factor became horizontal or dropped sharply.

\section{Third stage: Discriminant validity}

The capacity of the index to distinguish diet quality in different population groups was verified. Mean scores were compared for the BHEI-R components for individuals aged $\geq 20$ by sex and smoking using the Wald test (analysis of weighted variance)

\section{Fourth stage: Reliability}

Cronbach's alpha $(\alpha)$ was calculated, based on the mean of inter item correlations between 0 and 1 to evaluate internal consistency between the components of the BHEI-R. ${ }^{2}$ The higher the alpha, the greater the reliability of the scale; in this case, the sum of the scores of the items considered. Value $\geq 0.7$ shows acceptable reliabilty, ${ }^{19}$ although in the literature inter item correlations $>0.6$ are accepted.,21

The influence of the components on the total score was verified, examining the correlation of each component with the final score for the BHEI-R.

With the exception of the PCA, the other results, with the necessary adjustments, were obtained according to the sample design using the survey module of the Stata

\footnotetext{
a Ministério da Saúde, Secretaria de Atenção à Saúde, Coordenação-Geral da Política de Alimentação e Nutrição. Guia alimentar para a população brasileira: promovendo a alimentação saudável. Brasília (DF); 2006. (Série A. Normas e Manuais Técnicos).

${ }^{b}$ Gorgulho B, Marchioni DML, Conceição AB, Steluti J, Mussi MH, Nagai-Manelli R, et al. Quality of diet of working college students. Work. 2012;41(Suppl 1):5806-9. DOI:10.3233/WOR-2012-0958-5806
} 
Table 1. Distribution of scores and shares for each component in the Brazilian Healthy Eating Index - Revised (BHEI-R). Sao Paulo, SP, Southeastern Brazil, 2012.

\begin{tabular}{|c|c|c|c|c|c|}
\hline \multirow[b]{2}{*}{ Components } & \multicolumn{4}{|c|}{ Score (points) } & \multirow[b]{2}{*}{20} \\
\hline & 0 & 5 & 8 & 10 & \\
\hline Total fruit ${ }^{a}$ & 0 & 1.0 portion $/ 1,000 \mathrm{kcal}$ & & & \\
\hline Whole fruit ${ }^{b}$ & 0 & 0.5 portion $/ 1,000 \mathrm{kcal}$ & & & \\
\hline Total vegetables ${ }^{\mathrm{c}}$ & 0 & 1.0 portion $/ 1,000 \mathrm{kcal}$ & & & \\
\hline Veveald $^{\mathrm{d}}$ & 0 & 0.5 portion $/ 1,000 \mathrm{kcal}$ & & & \\
\hline Total grains ${ }^{\mathrm{e}}$ & 0 & 2.0 portion $/ 1,000 \mathrm{kcal}$ & & & \\
\hline Whole grains & 0 & 1.0 portion $/ 1,000 \mathrm{kcal}$ & & & \\
\hline Milk and dairy products ${ }^{f}$ & 0 & & & 1.5 portion $/ 1,000 \mathrm{kcal}$ & \\
\hline Meat, eggs and legumes & 0 & & & 1.0 portion $/ 1,000 \mathrm{kcal}$ & \\
\hline Oilsg & 0 & & & 0.5 portion $/ 1,000 \mathrm{kcal}$ & \\
\hline Saturated fat & $\geq 15$ & & 10 & $\leq 7 \%$ of TEV & \\
\hline Sodium & $\geq 2,0$ & & 1,0 & $\leq 0.75 \mathrm{~g} / 1,000 \mathrm{kcal}$ & \\
\hline Gord_AA & $\geq 35$ & & & & $\leq 10 \%$ do VET \\
\hline
\end{tabular}

Gord_AA: calories from solid fats, alcohol and added sugar; TEV: total energy value

${ }^{a}$ Including fruit and fruit juices

${ }^{\mathrm{b}}$ Excluding fruit juices

' Including legumes only after maximum score for meat, eggs and legumes is reached

${ }^{\mathrm{d}}$ Veveal = dark green and orange vegetables and legumes (only after maximum score for meat, eggs and legumes is reached)

e Total cereals = represents the groups of cereals, roots and tubers

${ }^{\mathrm{f}}$ Including soy-based milk and dairy products

${ }^{g}$ Including mono and polyunsaturated fats, oilseeds and fish oils

software program, version 10.0 (Stata Corporation Houston, USA) adopting $\mathrm{p}<0.05$ as the critical value.

The main research project was approved by the Ethics Committee of the Faculdade de Saúde Pública of the Universidade de São Paulo (Process No. 13/2001).

\section{RESULTS}

Using content analysis, it was verified that the components of the BHEI-R included six of the seven guidelines in the Food Guide for the Brazilian Population. ${ }^{a}$ The index did not evaluate the recommendation to drink two liters of water a day, or two special guidelines which encouraged doing physical activity and emphasized the importance of food hygiene (Table 2).

Weak correlation was observed between the scores for the components of the BHEI-R and energy consumption: eight components showed inverse correlation (Table 3). The low correlation between the scores and energy suggests they are independent.

The scree plot of the PCA (Figure) shows the presence of four factors with eigenvalues $>1$, representing $67 \%$ of total variance in the index.

The discriminant validity of the index was observed comparing smokers and non-smokers. The mean of the scores of six components of the BHEI-R was smaller for the smokers: total fruit, whole fruit, total grains, milk and dairy products, oil and sodium. The total mean score of the BHEI-R was higher for non-smokers compared to smokers (56.8 and 55.4; respectively, $\mathrm{p}<0.05$ ) (Table 4). This discrimination is similar to that observed when comparing the mean total score of the index for men and for women (55.3 and 56.9; respectively, $\mathrm{p}<0.05$ ). Four components also had smaller means for men: total fruit, whole fruit, total cereal and milk and dairy products (values not shown in the table).

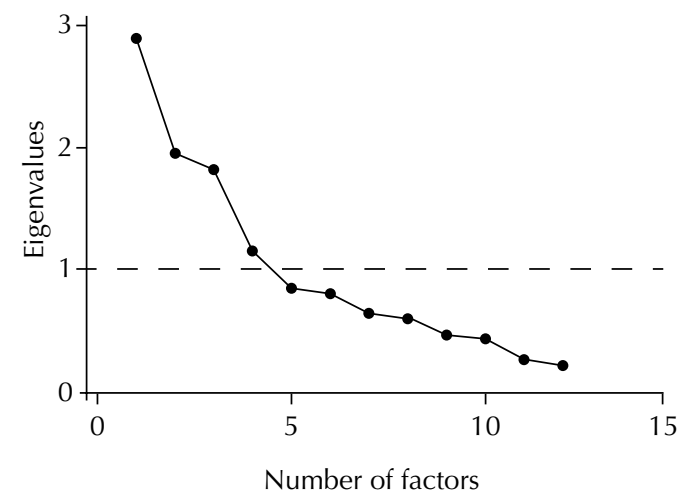

Figure. Scree plot of analysis for the principal components in the Brazilian Healthy Eating Index - Revised (BHEI-R). Sao Paulo, SP, Southeastern Brazil, 2003. 
Table 2. Mapping of the components of the Brazilian Healthy Eating Index - Revised (BHEI-R) according to recommendations from the Food Guide for the Brazilian Population. Sao Paulo, SP, Southeastern Brazil, 2012.

\begin{tabular}{lcc}
\hline Recommendations in the Guide & $\begin{array}{c}\text { Component of the } \\
\text { BHEI-R }\end{array}$ & Observations on the BHEI-R \\
\hline & Guidelines 1 and 6 & \\
\hline $\begin{array}{l}\text { Limit intake of saturated fats, replacing with } \\
\text { unsaturated and eliminating trans }\end{array}$ & $\begin{array}{c}\text { Saturated fat } \\
\text { The component "saturated fat" evaluates the } \\
\text { nutrient intake, following recommendations of the } \\
\text { Food Guide and the guidelines of the Brazilian } \\
\text { Society of Cardiology. }\end{array}$
\end{tabular}

Saturated fat should not exceed $10 \%$ of daily needs, as with simple sugars Choose vegetable oils, olive oil and margarines free of trans fatty acids

The component "oil" represents the intake of vegetable oil, fish fat and oilseeds, foods for which consumption is encouraged. In the Food Guide oilseeds are part of legumes, but are cited as good sources of unsaturated fat.

Reduce consumption of salt and processed The salt is reflected in the component "Sodium". foods

Gord_AA Trans fats are reflected in calories from solid fats, which belong to the group "Gord_AA" along with added sugar and alcohol. Cholesterol is not included in the Index.

Maintain energy balance and a healthy weight

The BHEI-R does not evaluate energy intake or physical activity.

\begin{tabular}{|c|c|c|}
\hline & Guideline 2 & \\
\hline \multirow[t]{2}{*}{$\begin{array}{l}\text { Consuming foods rich in complex } \\
\text { carbohydrates, preferably whole grain }\end{array}$} & $\begin{array}{c}\text { Total cereal } \\
\text { Whole grains }\end{array}$ & $\begin{array}{l}\text { As there is no recommendation for whole grains } \\
\text { intake the BHEI-R established intake of at least } 1 \\
\text { portion } / 1,000 \mathrm{kcal}\end{array}$ \\
\hline & Guideline 3 & \\
\hline \multirow{4}{*}{$\begin{array}{l}\text { Vary the fruits and vegetables, increasing } \\
\text { the supply of fiber and vitamins, such as } \\
\text { carotenoids, present in dark green and } \\
\text { orange vegetables }\end{array}$} & $\begin{array}{c}\text { Total fruit } \\
\text { Whole fruit }\end{array}$ & \multirow[t]{3}{*}{$\begin{array}{l}\text { Variety is evaluated in the BHEI-R. Whole fruit and } \\
\text { subgroups of vegetables are emphasized }\end{array}$} \\
\hline & $\begin{array}{c}\text { Total vegetables and } \\
\text { legumes }\end{array}$ & \\
\hline & $\begin{array}{l}\text { Dark green and } \\
\text { orange vegetables } \\
\text { and legumes }\end{array}$ & \\
\hline & Guideline 4 & \\
\hline \multirow{4}{*}{$\begin{array}{l}\text { Combine daily intake of legumes with } \\
\text { cereal grains, forming complete sources of } \\
\text { protein }\end{array}$} & $\begin{array}{l}\text { Meat, eggs and } \\
\text { legumes }\end{array}$ & \multirow{3}{*}{$\begin{array}{l}\text { Being a habit of Brazilians, legumes contribute } \\
\text { initially to the meat group, supplying proteins and, } \\
\text { subsequently to the group of vegetables for the } \\
\text { contribution of minerals and fiber. }\end{array}$} \\
\hline & $\begin{array}{c}\text { Total vegetables and } \\
\text { legumes }\end{array}$ & \\
\hline & $\begin{array}{l}\text { Dark green and } \\
\text { orange vegetables } \\
\text { and legumes }\end{array}$ & \\
\hline & Guideline 5 & \\
\hline Choose lower fat milk and dairy products & $\begin{array}{l}\text { Milk and dairy } \\
\text { products }\end{array}$ & \multirow{2}{*}{$\begin{array}{l}\text { The choice of whole milk, and fatty meats will } \\
\text { lower the score of the "saturated fat" and "Gord_ } \\
\mathrm{AA}^{\prime \prime} \text { components. The same will happen when } \\
\text { choosing processed meats, also influencing the } \\
\text { score decrease of the "sodium" component. }\end{array}$} \\
\hline $\begin{array}{l}\text { Choose leaner meats and avoid processed } \\
\text { meats }\end{array}$ & $\begin{array}{l}\text { Meat, eggs and } \\
\text { legumes }\end{array}$ & \\
\hline
\end{tabular}

Gord_AA: calories from solid fats, alcohol and added sugar

With regards reliability, the value of Cronbach's alpha $(\alpha=0.7)$ indicates the presence of internal consistency between the components of the BHEI-R. The correlations between the components' scores and the final score were weak. The Gord_AA component (composed of total calories coming from solid fats, alcohol and added sugar) was the most strongly correlated $(\mathrm{r}=0.75)$, followed by total fruit and whole fruit $(\mathrm{r}=0.50$ and $\mathrm{r}=0.48$, respectively) (Table 3 ).

\section{DISCUSSION}

The BHEI-R is reliable and structurally valid for evaluating the quality of diet in Brazilians. The content validity 
Table 3. Correlation of scores from the components of the Brazilian Health Eating Index - Revised (BHEI-R) with the final score and with energy intake. Sao Paulo, SP, Southeastern Brazil, 2003.

\begin{tabular}{|c|c|c|c|c|}
\hline Component & BHEI-R final $(r)$ & $\mathrm{p}$ & Energy $(\mathrm{kcal})(\mathrm{r})$ & $p$ \\
\hline Total fruit & 0.50 & $<0.001$ & -0.04 & 0.038 \\
\hline Whole fruit & 0.48 & $<0.001$ & -0.04 & 0.037 \\
\hline Total vegetables & 0.34 & $<0.001$ & -0.06 & 0.006 \\
\hline Veveal & 0.36 & $<0.001$ & -0.08 & $<0.001$ \\
\hline Total grains & 0.14 & $<0.001$ & -0.08 & $<0.001$ \\
\hline Whole grains & 0.09 & $<0.001$ & 0.02 & 0.290 \\
\hline Milk and dairy products & -0.02 & 0.304 & -0.02 & 0.236 \\
\hline Meat, eggs and legumes & 0.28 & $<0.001$ & 0.06 & 0.004 \\
\hline Oils & 0.46 & $<0.001$ & -0.14 & $<0.001$ \\
\hline Sodium & -0.18 & $<0.001$ & 0.19 & $<0.001$ \\
\hline Gord_AA & 0.75 & $<0.001$ & -0.30 & $<0.001$ \\
\hline Saturated fat & 0.47 & $<0.001$ & -0.19 & $<0.001$ \\
\hline
\end{tabular}

Veveal: dark green and orange vegetables and legumes; Oils: vegetable oils, oilseeds and fish oils; Gord_AA: total calories from solid fats, alcohol and added sugar

was upheld as the index included the principle Ministry of Health recommendations.

Individuals who have an energy dense diet tend to consume a greater quantity of foods of low nutritional value and probably received lower scores for the BHEI-R, according to the correlation of the score of the Gord_AA component with energy consumed. Thus, as in the validation of the HEI-2005, ${ }^{c}$ the scores of all components had a weak correlation with energy, suggesting that both indices evaluate dietary quality independent of the quantity of energy consumed. The advantage of using indexes like the BHEI-R is that the calculation, based on energy density (portion/1,000 kcal) or on calorie share in the diet, reduces the effect of total energy intake on the index.

The BHEI-R does not directly evaluate the quantity of energy consumed as it is a qualitative index. However, the variable can be dealt with as continuous or in categories of terciles, meaning that the quality of the diet can be linked to epidemiological outcomes related to energy consumption, as when Body Mass Index is used.

The points that contribute to the total score of the index may accumulate in different ways. It is probable that more than one dietary standard exists which deems a diet to be healthy or less healthy. For this reason, the indices can be linked to other analyses such as that of Cluster, defining dietary standards and comparing with individuals' diet, as in the study conducted by Ben-Shalom et al (2012). ${ }^{\mathrm{d}}$

The index shows the ability to distinguish groups with known differences in dietary quality, irrespective of energy intake. Smokers had a worse quality diet, as described in the literature ${ }^{5,6}$ and in the evaluations of the HEI-2005 in the study by Guenther et al (2008). ${ }^{12}$ Women had a better quality diet, as has been shown in other studies, including that by Ervin ${ }^{7}$ (2011) which assessed the data from the National Health and Nutrition Examination Survey (NHANES) 2003-2004. Women tend to adhere more to the recommendations in the American Food Guide, especially for the fruit and vegetable group, with a slightly higher score in the HEI-2005 (60.3 compared with 54.8 for men).

Comparing the results obtained from the PCA of the BHEI-R with those of the HEI-2005, there are four factors with eigenvalues $>1$, compared with five in the American index. The same methodology was used to extract the factors in both studies, however, the quantity of total explained variance, $67 \%$, cannot be compared with that of the HEI-2005, as Guenther et al (2007) ${ }^{\mathrm{c}}$ did not describe this value.

However, the PCA indicates that no single linear combination is responsible for a substantial proportion in the variation of eating patterns. The Food Guide itself ${ }^{a}$ emphasizes the importance of a varied diet, aiming the guidelines based on food groups and dietary standards, making it easy for the target audience to understand.

Individuals' nutrient intake depends on their food choices, which are influenced by cultural, social and demographic factors. The individual tends not to meet all standardized criteria. A diet may satisfy one standard for total cereals and milk and dairy products but not meet the standard for fruits. From an epidemiological point of

\footnotetext{
c Guenther PM, Reedy J, Krebs-Smith SM, Reeve BB, Basiotis PP. Development and evaluation of the Healthy Eating Index-2005: technical report. Alexandria, VA: U.S. Department of Agriculture, Center for Nutrition Policy and Promotion; 2007 [cited 2011 dec 2]. Available from: http://www.cnpp.usda.gov/HealthyEatingIndex.htm

${ }^{\mathrm{d}}$ Ben- Shalom Y, Fox MK, Newby PK. Characteristics and dietary patterns of healthy and less-healthy patterns in the low-income population. Alexandria, VA: Department of Agriculture, Food and Nutrition Service; 2012 (Nutrition Assistance Program Report Series). [cited 2012 sep 10]. Available from: http://www.fns.usda.gov/ora/MENU/Published/snap/FILES/Participation/HEI.pdf
} 
Table 4. Mean of the components and final score for the Brazilian Healthy Eating Index - Revised (BHEI-R) for individuals aged over 20 according to smoking. Sao Paulo, SP, Southeastern Brazil, 2003.

\begin{tabular}{lccccc}
\hline \multirow{2}{*}{ BHEl-R and components } & \multicolumn{2}{c}{$\begin{array}{c}\text { Smokers } \\
\mathrm{n}=626\end{array}$} & \multicolumn{2}{c}{$\begin{array}{c}\text { Non-smokers } \\
\mathrm{n}=904\end{array}$} & $\mathrm{p}$ \\
\cline { 2 - 5 } & Mean & Standard error & Mean & Standard error nn & 0.003 \\
Total fruit & 1.4 & 0.1 & 1.8 & 0.1 & 0.036 \\
Whole fruit & 1.2 & 0.1 & 1.5 & 0.1 & 0.556 \\
Total vegetables & 4.3 & 0.1 & 4.3 & 0.1 & 0.394 \\
Veveal & 3.9 & 0.1 & 3.7 & 0.1 & 0.050 \\
Total grains & 4.5 & 0.1 & 4.6 & 0.0 & 0.858 \\
Whole grains & 0.4 & 0.1 & 0.4 & 0.1 & 0.003 \\
Milk and dairy products & 3.6 & 0.2 & 4.2 & 0.2 & 0.009 \\
Meat, eggs and legumes & 9.0 & 0.1 & 8.5 & 0.1 & 0.042 \\
Oils & 9.7 & 0.1 & 9.9 & 0.0 & 0.030 \\
Sodium & 1.8 & 0.1 & 2.2 & 0.1 & 0.891 \\
Gord_AA & 9.8 & 0.4 & 9.9 & 0.3 & 0.9 \\
Saturated fat & 5. & 0.2 & 5.9 & 0.2 & 0.969 \\
BHEl-R total & 55.4 & 0.6 & 56.8 & 0.5 & 0.050 \\
\hline
\end{tabular}

Veveal: dark green and orange vegetables and legumes; Oils: vegetable oils, oilseeds and fish oils; Gord_AA: total calories from solid fats, alcohol and added sugar

view, diet represents a complex set of highly correlated exposures. A relationship between a food group and a disease may be wrongly assumed if only one single component and/or nutrient is studied. ${ }^{10,17}$

The Cranach's alpha of 0.7 suggests that the reliability of the BHEI-R is satisfactory. In studies using indexes developed in other countries, the alpha varied between 0.28 and $0.52 .^{12,18}$ The alpha found when validating the HEI-2005 was 0.43 . According to Nunnally ${ }^{19}$ (1978), values $\geq 0.7$ are deemed to indicate internal consistency; therefore, the BHEI-R has greater reliability with the Brazilian population than the HEI-2005 with the American population. Eliminating any of the BHEI-R components would not improve internal consistency, indicating the importance of the 12 components in the composition of the index. Correlations between the components and the final score may indicate how much each component contributes to variation in the total score. The Gord_AA component, followed by the total fruit and whole fruit components have the highest correlation with the final score for the index, i.e., those with a high BHEI-R score are likely to have lower consumption of solid fats, added sugar and alcohol, and an adequate intake of fruit.

A limitation of this study is that the BHEI-R was not compared with a gold standard instrument for evaluating dietary quality. In order to evaluate the HEI-2005, the authors compared the index with menus based on recommendations developed by the US Department of Agriculture, ${ }^{\mathrm{e}}$ National Heart Lung and Blood Institute, ${ }^{\mathrm{f}}$ Harvard Medical School's Healthy Eating Pyramid ${ }^{22}$ and the American Heart Association's No-Fad Diet.g,h As Brazil does not have recommendations based on menus, it was not possible to use this method. However, criteria such as biochemical markers may serve as a gold standard for come components based on nutrients.

Comparison with other dietary quality indexes may serve to evaluate the instrument and assess its capacity to detect changes in the population over time, analyzing mean values of total BHEI-R scores and the scores for the components at two different points in time. Another important evaluation is the capacity of the index to predict death and disease. Such validity of predictive criteria should use the BHEI-R linked to longitudinal studies that contain data on health and mortality. Similar research has already been carried out with the HEI-2005. $9,15,16$

The BHEI-R has good reliability and has been shown to be valid for used as an instrument to evaluate and monitor Brazilians' quality of diet. It may assist in producing data which support the planning of public policies and future guidelines. Possible future research includes additional tests such as predictive validity and even further adaptation for specific sub-populations.

\footnotetext{
e US Department of Agriculture, Center for Nutrition Policy and Promotion. Sample menus for a 2000 calorie food pattern. Alexandria, VA; 2006 [cited 2011 Dec 2]. Available from: http://www.mypyramid.gov/downloads/sample_menu.pdf

${ }^{f}$ U.S. Department of Health and Human Services, National Institutes of Health, National Heart Lung and Blood Institute. Your guide to lowering your blood pressure with DASH. Bethesda: National Heart Lung and Blood Institute; 2006. (NIH Publication Nº 06-4082). [cited 2011 Dec 2]. Available from: http://www.nhlbi.nih.gov/health/public/heart/hbp/dash/new_dash.pdf

${ }^{g}$ American Heart Association. No-fad diet sample menu plan: 1,200 calories. Alexandria; 2005 [cited 2011 Dec 2]. Available from: http:// www.americanheart.org/presenter.jhtml?identifier $=3031819$

${ }^{h}$ American Heart Association. No-fad diet sample menu plan: 2,000 calories. Alexandria; 2005 [cited 2011 Dec 2]. Available from: http:// www.americanheart.org/presenter.jhtml?identifier $=3031819$
} 


\section{REFERENCES}

1. Brown JD. The Cronbach Alpha Reliability Estimate. Shiken JALT Test Eval Sig Newsl. 2002;6(1):16-8.

2. Carmines EG, Zeller RA. Reliability and validity assessment. Thousand Oaks: Sage Publications; 1979. (Quantitative Applications in the Social Sciences, 17).

3. Castro MA, Barros RR, Bueno MB, César CLG, Fisberg RM. Trans fatty acid intake among the population of the city of São Paulo, Southeasthern Brazil. Rev Saude Publica. 2009;43(6):991-7. DOI:10.1590/S0034-89102009005000084

4. Cattell RB. The scree test for the number of factors. Multivariate Behav Res. 1966;1(2):245-76. DOI:10.1207/s15327906mbr0102_10

5. Dallongeville J, Marécaux N, Fruchart JC, Amouyel P. Cigarette smoking is associated with unhealthy patterns of nutrient intake: a meta-analysis. J Nutr. 1998;128(9):1450-7.

6. Ervin RB. Healthy Eating Index scores among adults, 60 years of age and over, by sociodemographic and health characteristics: United States, 1999-2002. Adv Data. 2008;(395):1-16.

7. Ervin RB. Healthy Eating Index - 2005 total and components scores for adults aged 20 and over: National Health and Nutrition Examination Survey, 2003-2004. Natl Health Stat Report. 2011;(44):1-9.

8. Fisberg RM, Slater B, Barros RR, Lima FD, Cesar CLG, Carandina L, et al. Índice de Qualidade da Dieta: avaliação da adaptação e aplicabilidade. Rev Nutr. 2004;17(3):301-18. DOI:10.1590/S1415-52732004000300003

9. Ford ES, Mokdad AH, Liu S. Healthy Eating Index and C-reactive protein concentration: findings from the National Health and Nutrition Examination Survey III, 1988-1994. Eur J Clin Nutr. 2005;59(2):278 -83. DOI:10.1038/sj.ejcn.1602070

10. Gordon T, Fisher M, Rifkind BM. Some difficulties inherent in the interpretation of dietary data from freeliving populations. Am / Clin Nutr. 1984;39(1):152-6.

11. Guenther PM, Reedy J, Krebs-Smith SM. Development of the Healthy Eating Index-2005. J Am Diet Assoc. 2008;108(11):1896-901. DOI:10.1016/j.jada.2008.08.016

12. Guenther PM, Reedy J, Krebs-Smith SM, Reeve BB. Evaluation of the Healthy Eating Index-2005.
J Am Diet Assoc. 2008;108(11):1854-64. DOI:10.1016/j.jada.2008.08.011

13. Kaiser HF. The varimax criterion for analytical rotation in factor analysis. Psychometrika. 1958;23(3):187-200. DOI:10.1007/BF02289233

14. Kennedy ET, Ohls J, Carlson S, Fleming K. The Healthy Eating Index: design and applications. J Am Diet Assoc. 1995;95(10):1103-8. DOI:10.1016/S0002-8223(95)00300-2

15. Koning LD, Chiuve SE, Fung TT, Willett WC, Rimm $E B, H u$ FB. Diet-quality scores and the risk of type 2 diabetes in men. Diabetes Care. 2011;34(5):1150-6. DOI: $10.2337 / \mathrm{dc} 10-2352$

16. Kuczmarski MF, Cremer Sees A, Hotchkiss L, Cotugna $\mathrm{N}$, Evans MK, Zonderman AB. Higher Healthy Eating Index-2005 scores associated with reduced symptoms of depression in an urban population: findings from the Healthy Aging in Neighborhoods of Diversity Across the Life Span (HANDLS) Study. I Am Diet Assoc. 2010;110(3):383-9. DOI:10.1016/j.jada.2009.11.025

17. Marchioni DML, Latorre MRDO, Eluf-Neto J, WünschFilho V, Fisberg RM. Identification of dietary patterns using factor analysis in an epidemiological study in São Paulo. Sao Paulo Med J. 2005;123(3):124-7. DOI:10.1590/S1516-31802005000300007

18. Miller PE, Mitchell DC, Harala PL, Pettit JM, Smiciklas-Wright H, Hartman TJ. Development and evaluation of a method for calculating the Healthy Eating Index-2005 using the Nutrition Data System for Research. Public Health Nutr. 2011;14(2):306-13. DOI:10.1017/S1368980010001655

19. Nunnally JC. Psychometric theory. 2.ed. New York; McGraw-Hill; 1978.

20. Previdelli AN, Andrade SC, Pires MM, Ferreira SRG, Fisberg RM, Marchioni DM. Índice de Qualidade da Dieta Revisado para população brasileira. Rev Saude Publica. 2011;45(4):794-8. DOI:10.1590/S0034-89102011005000035 8

21. Santos JRA. Cronbach's Alpha: a tool for assessing the reliability of scales. J Extension. 1999;37(2):1-5.

22. Willett WC. Eat, drink, and be healthy: the Harvard Medical School guide to healthy eating. New York: Free Press; 2001.

This study was supported by the Secretaria Municipal da Saúde de São Paulo (Process No. 027/2003) and by the Conselho Nacional de Desenvolvimento Científico e Tecnológico (CNPq - Process No. 502948/ 2003-5).

The authors declare that there are no conflicts of interest. 